\title{
Energy Intensity Development of the German Iron and Steel Industry between 1991 and 2007
}

\author{
Marlene Arens ${ }^{\text {a), 1)}}$, Ernst Worrell ${ }^{\text {b) }}$, Joachim Schleicha), c)
}

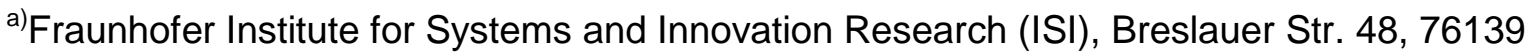
Karlsruhe, Germany.

b) Copernicus Institute of Sustainable Development, Utrecht University, Heidelberglaan 2, 3584 CS Utrecht, The Netherlands.

c) Grenoble Ecole de Management, 12, rue Pierre Sémard, BP127, 38003 Grenoble Cedex 01.

Keywords: energy efficiency, steel industry, energy intensity

1) Corresponding Author. Tel: +49 7216809 408, fax: +49 7216809 272, marlene.arens@isi.fraunhofer.de

\section{Introduction}

The global iron and steel industry is one of the largest industrial energy consumers and $\mathrm{CO}_{2}$ emitters. It accounts for about 3-5\% of the global $\mathrm{CO}_{2}$-emissions [5]. Germany is one of the largest steel making countries in the world with a production of nearly 44 Million tonnes in 2010, making it the largest steelmaker in Europe and the $7^{\text {th }}$ largest in the world.

Energy efficiency is one of the key measures to reduce $\mathrm{CO}_{2}$ emissions and energy consumption, as well as production costs. Estimating energy performance in the steel industry is a difficult task due to various reasons:

(1) Data on the energy consumption of the steel industry on an international level is often not accurate. Therefore, estimating energy efficiency in the steel industry in international comparisons is often surrounded with considerable uncertainties, as shown by Farla and Blok (2001) [9].

(2) Tanaka (2008) studied differences in the assessment of the energy performance in the steel industry. She points out that system boundaries of the analysis strongly influence the results. According to her findings the specific energy consumption (SEC) can vary from 16 to $21 \mathrm{GJ} / \mathrm{t}$ crude steel depending on the chosen boundaries [21]. 
(3) Data on the energy consumption in the steel industry is often aggregated at the sector level. Hence, data for the different processes are aggregated, making the calculation of the energy efficiency improvement per process (and over time) not possible.

Studies on energy efficiency in the steel industry can mainly be divided into two groups. First, studies on the comparison of the energy performance of the steel industry on an international level should be mentioned. Worrell et al. (1997) compared the specific energy consumption in selected countries (e.g. Germany, China, Brazil) between 1980 and 1991 using a decomposition method [25]. Kim and Worrell (2002) compared energy and $\mathrm{CO}_{2}$ intensity in the steel sector among seven countries [15]. Farla et al (1995) analyzed options for the reduction of $\mathrm{CO}_{2}$-emissions in industrial processes [10]. Studies by the International Energy Agency (IEA) show on a global level energy savings potentials and energy savings technologies [5].An in depth description of the production processes in the iron and steel sector, with a particular focus on best available low-emission techniques, may be found in the recent report by the European Commission's Joint Research Centre [x1]

Second, a set of studies exists on the energy performance of the steel industry of selected countries. Worrell et al. (2001) identified energy efficiency technologies for the steel industry in the US [24]. Zhang and Wang (2008) analyzed the influence of two energy efficiency technologies for selected steelworks in China between 1990 and 2000 using data on individual steel plants [26]. Wei et al. (2007) analyzed provincial panel data in order to estimate energy efficiency improvements in the Chinese state owned steel plants using the Malmquist Index Decomposition[22]. Ozawa et al. (2002) analyzed the development of the specific energy consumption in the steel industry in Mexico and estimated the effect of structural changes and efficiency improvements using a decomposition method [17]. Price et al. (2010) analyzed China's Top-1000 program which is designed to reduce energy consumption in the largest industrial companies [19]. Price et al. (2011) evaluated Chinas $11^{\text {th }}$ Five Year Plan concerning energy efficiency [18].

Due to the limited availability of disaggregated energy consumption data, most studies use decomposition methods to estimate the impact of structural changes (e.g. a production shift to an increased share of electric arc furnaces(EAF)), and energy efficiency improvements.

Studies on the energy performance of the German steel sector are rather limited. Lutz et al. (2005) used an integrated bottom-up/top-down approach to simulate policy-induced technological change, quantifying the shift from the BF/BOF (Blast Furnace / Basic Oxygen Furnace) route towards the EAFroute as well as priceinduced efficiency improvements for both routes [16]. Schumacher and Sands (2007) integrated bottom up information on iron- and steel-making technologies in a computable general equilibrium model for Germany to simulate macroeconomic effects of energy policies[20].Dahlmann et al. (2010) present a factsheet on energy efficiency measures including a list of energy efficiency technologies for each plant in the steel sector [27].Frondel et al. [11]analyze the specific energy consumption (expressed per tonneof crude steel) in Germany since 1990 using data on the sector level. They mention the influence of an increasing share of the EAF over the BF/BOF-route on the reduction of the SEC, but do not evaluate the impact of this development on overall energy use and intensity. Furthermore, the Stahlinstitut VDEh1 publishes annual reports on $\mathrm{CO}_{2}{ }^{-}$ 1 Stahlinstitut VDEh (Verein Deutscher Eisenhüttenleute) is an organization to support the techno-scientific
cooperation between engineers which work on steel technologies and the material steel. 
emissions of the iron and steel industry in Germany. They analyze in detail developments of the energy consumption of single (or groups of) energy carriers per process. However, in recent reports they do not publish the SEC for all energy carriers and processes. The reports also discuss activities to reduce $\mathrm{CO}_{2}$-emissions (e.g. diffusion of energy efficiency technologies) [12].

To summarize previous analyses we found that studies are restricted to aggregated levels as there is a lack of data on the process level. The conclusions of these studies are restricted to aggregated observations as well, e.g. showing the effect of structural changes on the development of the SEC. Furthermore we did not find any time series of the SEC in the iron and steel sector on the process level. Problems with data consistency occur if data stems form different sources.

In this paper we analyse data of the German Federal Statistical Office 2 on the energy consumption in the German iron and steel industry between 1991 and 2007. We calculate the SEC per process and show the development of the energy efficiency per process in the studied period. As we rely on a single consistent data source and choose a single set of process boundaries we expect accurate results on the development of the SEC, while accounting for the development of energy efficiency in the German iron and steel industry and calculating the impact of an increasing share of EAF. We first discuss the German iron and steel industry, followed by an introduction of the analysis methodology, assumptions and data used for the analysis. Next, we discuss the development of the SEC by process and for the German iron and steel industry as a whole. We end with discussion and conclusions.

\section{Methodology}

We analyze the development of the SEC of the main processes in the German iron and steel industry between 1991 and 2007 based on data of the German Federal Statistical Office. We expect to find improvements in energy efficiency due to technological progress, diffusion of best available technologies, retiring of older plants, and improved energy management. The period covers 16 years, which is sufficiently long to identify trends in energy efficiency improvement in the iron and steel industry. Furthermore the time period begins after German unification (1990), so that we could expect efficiency improvements due retiring plants in the former GDR. The analysis ends before the economic crisis in 2008/2009 due to data availability and to avoid efficiency effects from decreased capacity utilization.

The system boundaries of our quantitative analysis include input of energy carriers tothe preparation of ore, sinter plants, blast furnace operations, oxygensteelworks, electric steel works as well as hot rolling mills and cold rolling mills for sheets. Since we are interested at the development of the energy efficiency at the process level consumption for transportation, for example, is excluded in our analysis.

2Our analysis is based on data of the Eisen- und Stahlstatistik which was collected from the early 1960s till 2009. 
We define the specific energy consumption as primary energy use per unit of product. Energy use is defined as the sum of energy carriers per plant and year. To each plant we assign one product and to each energy carrier we assign a specific heating value.In German energy statistics all gases are reported as natural gas equivalent, hence the heating value is similar to that of natural gas (see Table 1). Throughout the paper we use the lower heating value (LHV) of the fuels. We include the following energy carriers: hard coal and hard coal briquettes, coke and coke breeze, other solid fuels, liquid fuels, gases (COG; BFG; BOFG, Natural Gas (NG), other gases) as well as electricity, steam and oxygen. Plants include sinter and ore preparation plants, blast furnace operations, electric steel works, (oxygen) steelworks, and rolling mills. Products are sinter, pig iron, electric steel, oxygen steel, and hot rolled steel, respectively.

We calculate the specific energy consumption for each product according to equation 1 :

$$
S E C_{j}=\left(\sum_{i} E C_{i} * m_{i}\right) / x_{j}(\text { Equation } 1)
$$

$S E C_{j}$ is the specific energy consumption for product $j ; E C_{i}$ refers to the heating value or the energy needed to produce energy carrier $i ; m_{i}$ is the amount of the consumed energy carrier $i$ to produce product $j ; x_{j}$ is the production of product $j$ in the investigated year in the German iron and steel Industry.

The energy consumption per plant is obtained by applying heating values to the energy carriers entering the plant. In the case of oxygen and steam, primary energy consumption for its production is used instead of a heating value. Electricity is accounted for based on the primary energy value. We assume an average power generation efficiency of $34.5 \%$ throughout the studied period. We do not include energy consumption for transportation nor for recycling and processing of by-product streams, other than included in the described processes.

Data is obtained from the German Federal Statistical Office which annually publishes the so-called Iron and Steel Statistics [3] for the German steel sector. These statistics provide data on the consumption of energy carriers used in different plants of the German steel industry. Some data is confidential, which is the case when three or less German companies provided data. Data may also be confidential to avoid identification of individual producers from the aggregated data. However, for this analysis we received the confidential data and it is incorporated in our analysis, without compromising confidentiality (see below).

We use a four-step approach in the analysis. First, for each process, we collect the consumption data of the different energy carriers in the investigated period. Then we calculate the energy consumption per energy carrier, process and year using the assumed heating values (see Table 1). In a third step we check how to treat confidential data. If for a single plant in a single year the energy consumption of three or more energy carriers are confidential then we aggregate the energy carriers and define them as 'Other Fuels'. If only the consumption of one or two energy carriers per process and year is confidential we either neglect them (i.e. when the total volume is very small, as for blast furnaces) or we interpolate (i.e. for rolling). Finally, we show the development of the SEC over time for each process. In the case of the blast furnace and BOF we also analyse the development of the net energy consumption, correcting for the production of fuels (i.e. gas recovery).

3 Fachstatistik Eisen und Stahl. 
Table 1: Assumed heating values 4 .

\section{Iron and Steelmaking Processes in Germany}

Currently there are four routes to produce steel. The main route is the primary route using blast furnace and basic oxygen furnace (BF/BOF) to produce steel from iron ore. The EAF route uses scrap as raw material and re-melts it in the Electric Arc Furnace (EAF). Two further routes exist, which are little or not used in Germany, i.e. direct reduction and smelting reduction. Direct Reduction reduces iron ore with the help of gas to Direct Reduced Iron (DRI), which is then fed to the EAF. This processis used in Germany by a single DRI-plant with an annual production of about $500,000 \mathrm{t}$ (or about $1 \%$ of German crude steel production). Worldwide 64.7 Mio t of DRI was produced in 2007, equivalent to a share of $5 \%$ of world crude steel production [23]. Smelting Reduction is a technology that produces crude steel from iron ore, without the need for coke production as used in the blast furnace. Only two processes are commercially used (i.e. Corex and Finex). A few plants have been built in Africa and Asia, though in Europe this technology has not been implemented so far. Figure 1 gives an overview of the steel producing routes in Germany.

Figure 1:Steel production routes in Germany.

\section{Blast Furnace / Basic Oxygen Furnace Route}

The main steel producing route in Germany and worldwide is the BF/BOF route.It is also the main route to produce steel from iron ore. Four processes belong to this route. First, iron ore is agglomerated to sinter in (1) sinter plants or in pellet plants. Pellet plants are most often located at the iron ore mine, and hence excluded from this analysis. Iron ore and fossil solid fuels (e.g. coke breeze) are mixed and baked at temperatures of about $1000^{\circ} \mathrm{C}$ after ignition in a gas-fired furnace. Therefore in sinter plants the main energy carrier is coke breeze. Electricity is required for fans, flue gas treatment equipment, conveyers and other electrical devices.

In the (2) coke oven, hard coal is converted to coke by removing volatile substances. Coke is a solid and porous energy carrier which sustains permeability in the blast furnace. Sinter and coke, as well as further substances are fed from the top to the (3) blast furnace. Hot wind at temperatures of about $1100^{\circ} \mathrm{C}$ from hot blast stoves is introduced at the bottom of the blast furnace to sustain the reduction of iron ore to iron[2]. The hot

\footnotetext{
4The heating value for hard coal varies slightly over time. Nevertheless, our analysis assumes a constant heating value for hard coal since it focuses on the development of energy efficiency at the process level. Also, from an empirical perspective, the heating values for coke and coke breeze hardly change over time. Heating values for gases are reported for the heating values of natural gas, thus we do not need to consider changing (variations in ?) heating values for gases. (I don't quite understand what you are trying to say here)
} 
stoves are mainly fed with the top gas of the blast furnaces, i.e. the blast furnace gas (BFG). The blast furnace is a shaft furnace which works in the counter flow principle. Sinter and coke are fed from the top while the reducing gas streams from the bottom to the top. Counter flows have the best heat transfer known. Temperatures in the blast furnace range from $2200^{\circ} \mathrm{C}$ at the bottom to $120^{\circ} \mathrm{C}$ at the top. The main chemical reaction in the blast furnace is the reduction of iron ore $\left(\mathrm{Fe}_{2} \mathrm{O}_{3}\right)$ to pig iron ( $\left.\mathrm{Fe}\right)$ with the help of carbon $(\mathrm{C})$ and releases carbon dioxide $\left(\mathrm{CO}_{2}\right)$. This step is the most energy intensive step in steelmaking. As a by-product Blast Furnace Gas (BFG) leaves the blast furnace at the top. BFG is a low energetic gas with a heating value of about $4 \mathrm{MJ} / \mathrm{Nm}^{3}[8]$. Pig iron contains about $4 \%$ carbon.

To produce crude steel, which contains about $1.5 \%$ carbon (or less), pig iron is fed to the BOF. Part of the carbon is removed by an exothermic reaction with oxygen to carbon monoxide (with repressed combustion) or carbon dioxide at temperatures of about $1700^{\circ} \mathrm{C}$ [7]. Basic Oxygen Furnace Gas (BOFG) is produced, containing about $70 \%$ carbon monoxide $(\mathrm{CO})$ and has a heating value of about $9 \mathrm{MJ} / \mathrm{Nm}^{3}$ [7]. If basic oxygen furnace gas $(B O F G)$ is recovered, BOFs could be net energy producers. Main energy carriers are oxygen, electricity, Natural Gas (NG), Coke Oven Gas (COG) and steam.

Blast furnaces are usually located in integrated steelworks along with sinter plants, basic oxygen furnaces, rolling mills, a power plant and often coke ovens. Top gases and by-products are reused in other plants. BFG is fed to the hot stoves; BOFG is used for reheating furnaces in hot rolling mills, or for power generation. Figure 2 shows the system of energy flows in integrated steel works. Although coke ovens are located and energetically embedded within integrated steelworks, within energy statistics they are not associated with the steel sector but to the energy conversion sector.

Figure 2: Energy flows in an integrated steel work [1]

\section{Electric Arc Furnace Route}

To recycle steel, scrap is melted in the EAF. Scrap and additives are fed from the top into the furnace and are heated by an electric arc. The temperature of the molten steel can increase up to $1800^{\circ} \mathrm{C}$. Oxygen and other fuel gases are injected in order to accelerate the melting process. This process requires only about one third of the energy needed in the BF/BOF route to produce steel as the main energy intensive step in the steel sector (i.e. the reduction of iron ore to iron) has been carried out in the BF/BOF route. 
Secondary metallurgy or ladle refining improves the quality of the liquid steel which leaves the BOF or the EAF. This is done in vacuum degassing plants or ladle furnaces. In energy statistics secondary metallurgy is assigned to the steel making process (i.e. BOF or EAF).

Ingot Casting means pouring liquid steel into stationary molds to form ingots. Only $3 \%$ of crude steel in Germany is cast in ingots. The dominant route to produce semi-finished billets, blooms or slabs is continuous casting[3].

In hot rolling mills semi-finished steel products are first heated to a temperature of about $1200^{\circ} \mathrm{C}$ and then rolled to sheets or long products. The main energy carriers are gas for the furnaces and electricity for the rolling mill. Cold Rolling includes pickling, rolling, annealing and skin pass rolling in order to produce coils with a gauge as low as $0.15 \mathrm{~mm}[2]$.

\section{Steel Production by process in Germany 1991-2007}

Figure 3 shows the development of the steel production per process in Germany from 1991-2007. While the production of BF/BOF steel varies between 29 and $33.5 \mathrm{Mt} / \mathrm{year}$, the production of EAF-steel increases constantly from 8.5 to $15.0 \mathrm{Mt} / \mathrm{year}$. From 1991-1993 there is also a small share of Open Hearth or SiemensMartin (SM) steel that was produced by a single plant in the former $\mathrm{GDR}^{5}$. With $0.8,0.5$ and $0.6 \mathrm{Mt} \mathrm{SM}$ steel production had a share of $1.3-1.8 \%$ of the total steel production in Germany in those years [3].

Figure 3: Steel production (in Mt/year) in Germany per process from 1991-2007 (Data from [3]).

\section{Results}

\subsection{Sinter and Ore Preparation Plants}

Apart from sinter plants the statistical group furthermore covers ore preparation plants (e.g. crushing, milling, filtering, ore blending beds). Unfortunately, no separate information about the energy consumption of the ore preparation plants is available. But their main energy carrier should be electricity, which amounts for 15 to $22 \%$ of the total energy consumption of this group.

In contrast to our expectations,energy intensity of the sinter plants did not decrease continuously. We even find an increase of the SEC between 1991 and 1998 and between 2002 and 2006. The SEC peaks in 1998 with $2.28 \mathrm{GJ} / \mathrm{t}$ sinter. This is $0.26 \mathrm{GJ} / \mathrm{t}$ sinter or $12 \%$ higher than in $1991(2.04 \mathrm{GJ} / \mathrm{t})$. The first increase is caused by an increase in the consumption of coke breeze. The second increase (2002-2006) results from am increase in hard coal consumption. The specific consumption of electricity, coke oven gas and natural gas remain more or less constant over the studied period.

5 German Democratic Republic (1949-1990) 
Figure shows the development of the SEC of sinter and ore preparation plants per tonne sinter. The main energy carrier is coke breeze with a share of 63 to $74 \%$ of the total energy consumption. The group 'other fuels' strongly increases over the investigated period. The main driving factor for this increase is the partly substitution of coke breeze with hard coal. In 1998 hard coal amounted for $0.20 \mathrm{GJ} / \mathrm{t}$ sinter and its share increased till 2007 to $0.30 \mathrm{GJ} / \mathrm{t}$ sinter. Between 1998 and 2007 hard coal accounts for $60-80 \%$ of the fuels within the group 'other fuels'. Coke oven gas and natural gas make up between 4 to $6 \%$ of the total energy consumption.Ghenda (2009) assumes that the increased energy intensity in sinter plants since 2003 is due to increased basicity $\left(\mathrm{CaO} / \mathrm{SiO}_{2}\right)$ of the used ores $(2003: 1.72,2007: 2.07)$ [12].

Figure 4: Specific energy consumption in sinter plants, expressed in primary energy per tonne of sinter.

\subsection{Blast Furnace Operations}

Besides blast furnaces this group includes plants for the transport of ore, hot stoves, water treatment, blast furnace gas treatment and pumps. Reducing agents blown into the blast furnaces are included as well. Power may be recovered from the top gas through pressure recovery turbines. The only DRI plant in Germany belongs also to this group. With an annual production of approximately $500.000 \mathrm{t}$ we neglect its influence. The energy carriers are mainly reducing agents for the blast furnaces [4].

Due to confidentiality, we neglect the use of basic oxygen furnace gas, coke breeze and other solid fuels. For the published years BOFG and coke breeze amount to a maximum of total energy consumption of $0.5 \%$ and $0.6 \%$ respectively. Other solid fuels are zero, except in 1992. Hard coal consumption is confidential in 2002 and 2003. We therefore interpolate these values from the specific hard coal consumption of 2001 and 2004.

Figure 5 shows the specific energy input in blast furnace operations. The main energy carrier is coke, though its consumption was partly reduced by injecting hard coal in the studied period. In 1991 coke consumption amounted for $93 \%$ of the total SEC, or $11.64 \mathrm{GJ} / \mathrm{t}$. The specific coke consumption was reduced by $14 \%$ from 1991 to 1999 . Coke consumption increased from $10.06 \mathrm{GJ} / \mathrm{t}$ to $10.66 \mathrm{GJ} / \mathrm{t}$ from 1999 to 2000 . From 2000 onwards, coke consumption decreased continuously to $10.18 \mathrm{GJ} / \mathrm{t}$ though in 2006 and 2007 its consumption increased slightly again. In 2007 coke is only $88 \%$ of the total energy consumption in the blast furnace. The specific hard coal consumption has nearly doubled in the studied period, from $1.74 \mathrm{GJ} / \mathrm{t}$ in 1991 to $3.09 \mathrm{GJ} / \mathrm{t}$ in 2007. We found a reduction in the use of liquid fuels. The consumption of blast furnace gas and electricity remained almost constant while the consumption of natural gas and oxygen increased slightly.

The reduction of iron ore to iron in the blast furnaces produces blast furnace gas (BFG), and is used as an energy carrier within the integrated iron and steel plants. It is mainly used to heat the hot stoves and to produce electricity in onsite power plants. To calculate the net SEC of blast furnace operations we reduce the specific energy input by the specific amount of BFG production. 12 out of 15 blast furnaces in Germany are equipped with Top Pressure Recovery Turbines (TRT). The remaining three blast furnaces are either too small, have a too low pressure, or are planned to be equipped with a TRT [13]. In this study the electricity 
output of the TRTs is not treated as a credit, as its production value is summed up with the electricity output of the onsite power plants. Hence, no time series of the TRT electricity output is available.Yet for the year 2003 its production is published and has a value of $440 \mathrm{GWh}$, which equals $0.05 \mathrm{GJ} / \mathrm{t}$ pig iron or $5.8 \%$ of the electricity consumed in blast furnaces [6]. Figure 6 shows the specific net energy consumption of blast furnace operations in the German steel sector between 1991 and 2007. Apart from 2003 we observe with some exceptions a slight and continuous decrease of the net SEC by $3.8 \%$ over the studied period, equalling about $0.2 \% /$ year.

Our analysis of the blast furnace operations shows slight reductions of the SEC. Bear in mind that due to confidentiality we neglected the influence of basic oxygen furnace gas, coke breeze, and other solid fuels, which equals about $1 \%$ of total energy use in the BF. The specific net energy consumption and the specific energy input were reduced by average $0.2 \% /$ year.

Figure 5: Specific energy input in blast furnace operations, expressed in primary energy per tonne of pig iron.

Figure 6: Specific primary net energy consumption in blast furnace operations.

\subsection{Basic Oxygen Furnace}

From 1991 to 2002 in energy statistics the group was called Oxygensteelworks. From 2003 onwards the group is called Other Steelworks, though the same group of plants is included. In 1991 there were 38 BOFvessels operating in Germany. This number was reduced to 21 in 2007 of which only 18 were operating at that time [3].

Due to confidentiality we aggregate the following energy carriers as Other Fuels: hard coal, coke, coke breeze, other solid fuels, liquid fuels, BFG, BOFG, and other gases.

The production of BOFG was published firstly in 1993. We analyze the net energy consumption from 1993 onwards, whilewe show the specific energy input from 1991 onwards.

Figure 7shows the specific energy input in the BOF in Germany between 1991 and 2007. The two main energy carriers are oxygen and electricity each amounting for about $0.40 \mathrm{GJ} / \mathrm{t}$. While the consumption of oxygen remained approximately on the same level, the consumption of electricity was reduced by $16 \%$ between 1991 and 1997 and then increased again to approximately the same amount as in 1991. The specific consumption of natural gas, coke oven gas and other fuels were reduced over the studied period while the specific consumption of steam slightly increased.

To calculate the net energy consumption of the BOF we reduce the specific energy input by the specific BOFG production. Figure 8 shows the specific net energy consumption of BOFG in Germany between 1993 
and 2007. We found a net SEC for 1993-1995 and 1995-2007 of about $0.39 \mathrm{GJ} / \mathrm{t}$ oxygen steel and about $0.61 \mathrm{GJ} / \mathrm{t}$, which equals an increase of about $56 \%$.

Our analysis shows a strong decrease in the specific energy input in BOFs between 1991 and 1994 by 13\%. Main drivers are the reduction of electricity, natural gas, and other fuels. But from 1995 to 1999 the specific energy input increased by $8 \%$ and this level was roughly kept till 2007. Main drivers for this development were an increase in the consumption of electricity and steam.

Figure 9 shows the specific BOFG production in the studied period. The increase of the specific net energy consumption originates from the reduction of the BOFG production. Between 1994 and 19963 BOFs have been shut down [3]. According to the StahlinstitutVDEh among these 3 BOFs have been some with BOFG recovery. Currently only about $60 \%$ of the BOFs in Germany are equipped with BOFG recovery systems [13].

Figure 7: Specific energy input to basic oxygen furnaces expressed in primary energy per tonne oxygen steel

Figure 8: Specific primary net energy consumption in basic oxygen furnaces, expressed in primary energy per tonne of oxygensteel

Figure 9: Specific BOFG production, expressed in energy (LHV) per tonne of oxygen steel.

\subsection{Electric Arc Furnace}

From 1991 to 2002 in the statistics electric steel works are in one group with so called 'Other Steelworks'. Therefore this group also contains Siemens-Martin-Furnaces from 1991 to 1993 . These furnaces were run in the former GDR and were shut down in 1993. In the data we cannot distinguish electric arc furnaces from Siemens-Martin-Furnaces in this period therefore we start our analysis of electric arc furnaces in 1994. The name of the group was changed in 2003 to 'Electric Steel Works'. We might observe statistical differences from 2002 to 2003.

The SEC of electric steel works varies only slightly over the studied period. Taking 1994 as the reference, the SEC varies between $+2 \%$ (e.g. in 1996, 2004 and 2007) and $-2 \%$ (in 1998). In 2003 the SEC is $4 \%$ lower than the year before. Over the total period studied, we see no real improvement in energy efficiency of electric steel works in Germany between 1994 and 2007.

Figure 10 shows the development of the consumption of the different energy carriers. The main energy carrier is electricity accounting for 86 to $88 \%$ of the total SEC. Natural gas and oxygen count for $5-7 \%$ and $3-4 \%$ respectively. Steam and other fuels amount for 2-3\%. In 2006, the same amount of electricity per tonne electric steel was used than in 1994. We observe a slight increase in the use of oxygen (1994: $0.21 \mathrm{GJ} / \mathrm{t} ; 2007: 0.26$ 
$\mathrm{GJ} / \mathrm{t}$ ) and a slight decrease in the use of steam (1994: $0.05 \mathrm{GJ} / \mathrm{t} ; 2007: 0.03 \mathrm{GJ} / \mathrm{t})$. The use of natural gas and other fuels remained nearly constant over the studied period.

We would have expected at least a slight energy efficiency improvement due to technological progress such as process management and increased usage of oxygen. It might be that the scrap quality decreased as there was a big demand for scrap especially from Asia (i.e. China) between 2000 and 2007. Under these circumstances we could suspect that without any technological progress energy efficiency would have decreased in this period. However, there is insufficient data on scrap quality and the impact on the EAF SEC to evaluate this hypothesis.

Figure 10: Specific energy consumption in electric arc furnaces, expressed as primary energy consumption per tonne of electricsteel.

\subsection{Rolling}

This group covers hot rolling mills as well as rolling turneries, hot extruder plants, finishing plants and glow systems as far as they belong to hot rolling mills. Cold rolling mills also belong to this group[4]. We refer the energy consumption of this group to the production of hot rolled steel. We neglect the influence of the other processes. The share of cold rolled steel of hot rolled steel decreased from $35.0 \% 1994$ to $31.4 \%$ in 2007 [3]. A decrease in the share of cold rolled steel could lead to a reduction in the specific energy consumption per tonne hot rolled steel.

Due to confidentiality we have to make assumptions for the use of other fuelsbetween 1999 and 2003, as well as 2006. In 1999 'other fuels' amount to $0.29 \mathrm{GJ} / \mathrm{t}$ hot rolled steel and in 2004 this is $0.34 \mathrm{GJ} / \mathrm{t}$. Therefore we assume for the years in between the following values: 0.295; 0.305; 0.314; 0.324 (2000-2003). For 2006 we assume $0.41 \mathrm{GJ} / \mathrm{t}$ for 'other fuels'.

For rolling we found a continuous decreasing energy intensity of about $1.4 \%$ per year, for nearly all energy carriers, although especially for coke oven gas and electricity.

The main energy carriers are natural gas and electricity which amountfor $1.24-1.52 \mathrm{GJ} / \mathrm{t}$ and $1.51-1.83 \mathrm{GJ} / \mathrm{t}$ respectively(Figure 11). The specific consumption of natural gas increased from 1991 to 2001 from $1.37 \mathrm{GJ} / \mathrm{t}$ to $1.52 \mathrm{GJ} / \mathrm{t}$. From 2002 onwards its consumption decreased to $1.24 \mathrm{GJ} / \mathrm{t}$ in 2007 , resulting in an efficiency improvement of $10 \%$ comparing to 1991 . The consumption of electricity continuously decreased from 1.83 $\mathrm{GJ} / \mathrm{t}$ to $1.51 \mathrm{GJ} / \mathrm{t}$, which equals $17 \%$ or $1.0 \%$ per year. The specific consumption of coke oven gas decreased continuously even stronger from $1.02 \mathrm{GJ} / \mathrm{t}$ to $0.38 \mathrm{GJ} / \mathrm{t}$ or $3.7 \%$ per year. The use of steam and oxygen was reduced by $2.1 \%$ and $2.9 \%$ per year respectively. The consumption of other fuels decreased from 1991 to 1998 from $0.40 \mathrm{GJ} / \mathrm{t}$ to $0.29 \mathrm{GJ} / \mathrm{t}$, but then increased till 2007 to $0.40 \mathrm{GJ} / \mathrm{t}$.

Several technological and logistic improvements contributed to the continuous decrease in the specific energy consumption. First, improved process management, and, secondly, the replacement of recuperative burners 
by regenerative burners, helped to reduce the specific fuel consumption (coke oven gas, natural gas). Due to improved logistics less waste was produced and therefore an improvement in energy efficiency was achieved. The usage of oxygen furthermore contributed to a decrease of the SEC[13]. Apart from these technological or logistic improvements the increase in the import of semi-finished products or a decreasing share of cold rolled steel could influence the reduction of the specific energy consumption in rolling. To evaluate this effect a detailed study of the imports of semi-finished products and the development of the cold rolled steel production in the studied period would be necessary, which is a topic for further study.

Figure11: Specific energy consumption in rolling, expressed as primary energy per tonne of hot rolled steel.

\subsection{Overall Trends}

As we base our analysis of the energy efficiency of the German steel industry on data on the energy consumption of the different processes, we can calculate, bottom up, the effect of the structural change towards an increasing share of EAF on the development of the specific energy consumption per tonne crude steel. While the production of BF/BOF-steel remained between 30 and $34 \mathrm{Mt} /$ year, the production of EAF-steel nearly doubled from $8.9 \mathrm{Mt}$ to $15 \mathrm{Mt} /$ year (see Figure 3). The share of EAF increased from $21.8 \%$ to $30.9 \%$.

Figure 12 shows the influence of the increase in the share of EAF production on the development of the SEC in Germany between 1994 and 20076. The dark line represents the development of the specific energy consumption per tonne crude steel based on the specific (net) energy consumption in blast furnace operations and electric arc furnaces. For the studied period we obtain a total decrease of $6.3 \%$ of the SECper tonne of crude steel, which equals an improvement of about $0.4 \% /$ year.

The dotted line represents the hypothetic development of the specific energy consumption per tonne crude steel for the case that the specific energy consumption per tonne BF/BOF steel and EAF-steel remained constant at 1994 levels, and only the production values are changing. We can now show the influence of an increasing share of EAF on the specific energy consumption per tonne crude steel. Efficiency improvements are not considered in the dotted line. We obtain that the specific energy consumption per tonne crude steel due to an increase of the share of EAF was reduced by $4.6 \%$ in the studied period. Based on this calculation, we conclude that due to changes in the processes the specific energy consumption per tonne crude steel was reduced by $0.3 \%$ between 1994 and 2007 . This equals a reduction of the specific energy consumption due to changes in the processes (among theses energy efficiency improvement is an option) of $0.1 \%$ per year.

6We exclude the years 1991-1993 in thiscalculation, asfortheseyears,inefficient SM-furnaceswereincluded in thegroupofelectricarcfurnaces. 
Figure 12: Illustration of the influence of a production shift to EAF on the reduction of the specific energy consumption (SEC) per tonne crude steel in the German Iron and Steel Industry between 1994 and 2007.The dark line shows the development of the SEC per tonne crude steel between 1994 and 2007 in the German Iron and Steel Industry. The dotted line represents the hypothetical development of the SEC per tonne crude steel for the case that the SEC per $t$ EAF- and per tonne BF/BOF-steel remained on the value of 1994 while only the production of $\mathrm{EAF}-$ and $\mathrm{BF} / \mathrm{BOF}$ steel changed.

\section{Discussion}

The specific energy consumption per tonne crude in the German steel industry between 1994 and 2007 decreased by $6.3 \%$ of which $4.6 \%$, or $0.3 \% / y e a r$, originates from the increase in the share of EAF production. Other effects among which energy efficiency improvements are an option result in a decrease in the specific energy consumption of $0.1 \% /$ year.

In rolling the SEC decreased continuously in the studied period by $1.4 \%$ per year. Yet in this study we cannot investigate the effect of production shifts or of increased shares of semi-finished products. The specific net energy consumption per tonne pig iron also decreased continuously but due to an increase of the top-gasproduction, which we treated as a credit. The specific energy input in blast furnace operations was in 2007 of about the same order than in 1991, without considering credits for TRT. The specific net energy consumption of basic oxygen furnaces increased strongly between 1993 and 1996 due to a decrease in the BOFG production. In electric arc furnaces the SEC remained relatively constant between 1994 and 2007. In sinter production the specific energy consumption even increased comparing 2007 to 1991.

These findings are based on data from the German Federal Statistical office on the energy consumption in the iron and steel industry in Germany between 1991 and 2007. In their quality report[4] on the statistics a relatively high accuracy is assumed, asdata is based on information from all steel producers in Germany and not just from a selected sample. Furthermore data was collected monthly and all data was validatedbased on the long-term experience of the institution. Finally, fluctuations in the sector are seldom,except for closure or mergers of companies.

Production data was obtained by the German Iron and Steel Association 7 and can be considered as the most accurate data available.Nevertheless, in our study there are two caveats. First, misallocation from production data to the statistical groupcan cause inaccuracies. As mentioned in 4.1 , the statistics allocate the energy consumption of sinter plants and ore preparation plants in one group, while our analysis assigns only the production of sinter to this group. Furthermore, hot rolling and cold rolling are summed in a single group in statistics, and we only consider hot rolled steel for the calculation of the SEC. Second, further uncertainties lie in the assumption of heating values and the set of boundaries. As our key analysis is the time series of the SEC, these uncertainties do not matter.

\footnotetext{
7 Wirtschaftsvereinigung Stahl
} 
Publications of the German Iron and Steel Association on the SEC per product show similar results with similar tendencies[3] as our research shows. They publish a reduction of the SEC per tonne crude steel between 1994 and 2007 of $10.3 \%$, which equals $0.8 \%$ per year. The association uses a different method to calculate the SEC though they rely on the same data sources. The association does not consider BFG and BOFG energy credits, neglecting the onsite consumption of these gases. Furthermore steam consumption is neglected in the association's method.

While differences in methodology and system boundaries do not allow for a quantitative comparison of our results to those found for other countries, we nevertheless present key findings from the seminal studies analysing the development of energy efficiency in the production of iron and steel in other countries than GermanyKim and Worrell (2002)provided $\mathrm{CO}_{2}$ intensities for the iron and steel industry in selected countries. They showed slight increases in the $\mathrm{CO}_{2}$ intensities from 1991 till 1994/1996 for India, China, the US, and Brazil. Only $\mathrm{CO}_{2}$ intensities for Mexico and Korea were slightly decreasing [15].Wei et al. (2007) found that the energy efficiency in the iron and steel sector in China improved by 6.7\% per year between 1994 and 2003[22]. Zhang and Wang (2008) published a decreasing SEC in the Chinese iron and steel industry of about $4.3 \%$ between 1990 and 2000[26].Guo and Fu (2009) showed that the SEC per process in the Chinese steel industry decreased constantly for virtually each process between 1995 and 2005. Only the efficiency of blast furnaces decreased from 2000 onwards[14]. Note that slight differences in system boundaries may affect the comparison of the trends. Hence, comparisons of trends should be done with care.

Energy efficiency of the processes in the German iron and steel industry between 1991 and 2007 did not improve significantly, apart from rolling. We identified potential to increase the recovery of BOFG. Assuming that energy efficiency would improve continuously over time due to the diffusion of new technologies(e.g. strip casting, top gas recycling blast furnace, smelting reduction, heat recovery from electric arc furnaces, heat recovery from slag) and improved process management, we expect further potential to improve energy efficiency. Therefore, we suggest detailed studies on the remaining potential to identify energy efficiency improvement options and study the diffusion of best practices, both in technology and management/operation.Finally, a similar empirical analysis as presented in this paper could be extended to also include the years of the recent financial crisis (2008/2009). Such an analysis may be expected to provide valuable insights into the effects of capacity utilisation on energy intensity in the iron and steel sector.

\section{Acknowledgements}

The authors would like to thank three anonymous reviewers for their valuable comments and suggestions, Roman Hartmann (German Federal Statistical Office)for providing the data for this study, and Tobias Fleiterof Fraunhofer ISI for his insightful comments on an earlier draft of this paper. 


\section{References}

[1] Stahl-Zentrum.

[2] International Iron and Steel Institute. Energy use in the steel industry. Brussels: 1998.

[3] Wirtschaftsvereinigung Stahl und StahlinstitutVDEhStatistischesJahrbuch der Stahlindustrie 2009/2010. Düsseldorf: 2009.

[4] Statistisches Bundesamt.QualitätsberichtFachstatistik Eisenund Stahl. Wiesbaden: 2011.

[5] International Energy Agency. Tracking industrial energy efficiency. 2007.

[6] AichingerH M. 6. $\mathrm{CO}_{2}$-Monitoring-Fortschrittsbericht der Stahlindustriein Deutschland. Düsseldorf: StahlinstitutVDEh; 2007.

[7] BrauerH (editor).Produktions- und produktintegrierter Umweltschutz. In: Handbuch des Umweltschutzes und der Umwelttechnik Band 2.Springer Verlag; 1996.

[8] Christen HR. Chemie. Verlag Sauerländer; 1976.

[9] FarlaJC, Blok K. The quality of energy intensity indicators for international comparison in the iron and steel industry. Energy Policy2001;29(7):523-43.

[10] Farla JC, Hendriks CA, Blok K. Carbon dioxide recovery from industrial processes. Energy Conversion and Management 1995;36(6-9):827-30.

[11] Frondel M,Grösche P,Halstrick-Schwenk M, Janßen-Timmen R, Ritter N. DieKlimavorsorgeverpflichtungder deutschen Wirtschaft-Monitoringbericht2009.Essen: Rheinisch-Westfälisches Institut für Wirtschaftsforschung; 2010.

[12] Ghenda JT. 9. $\mathrm{CO}_{2}$-Monitoring-Fortschrittsbericht der Stahlindustriein Deutschland -Berichtsjahr2009. Düsseldorf:StahlinstitutVDEh, 2010.

[13] Ghenda JT. Personal communication, 27.07.2011, 01.12.2011 and 02.12.2011.

[14] Guo Z, Fu Z. Current situation of energy consumption and measures taken for energy saving in the iron and steel industry in China. Energy 2010;35(11):4356-60.

[15] Kim Y,Worrell E. International comparison of $\mathrm{CO}_{2}$ emission trends in the iron and steel industry. EnergyPolicy 2002;30(10):827-38.

[16] Lutz C, Meyer B, Nathani C, Schleich J. Endogenous technological change and emissions: The case of the German steel industry. Energy Policy 2005;33(9):1143-54.

[17] Ozawa L, Sheinbaum C, Martin N, Worrell E, Price L. Energy use and $\mathrm{CO}_{2}$ emissions in Mexico's iron and steel industry. Energy 2002;27(3):225-39. 
[18] Price L, Levine MD, Zhou N, Fridley D, Aden N, Lu H, et al.. Assessment of China's energy-saving and emission-reduction accomplishments and opportunities during the 11th five year plan. Energy Policy 2011;39(4):2165-78.

[19] Price L, Wang X, Yun J. The challenge of reducing energy consumption of the top-1000 largest industrial enterprises in China. EnergyPolicy 2010;38(11):6485-98.

[20] Schumacher K, Sands RD. Where are the industrial technologies in energy-economy models? An innovative CGE approach for steel production in Germany. Energy Economics 2007;29(4):799-825.

[21] Tanaka K. Assessment of energy efficiency performance measures in industry and their application for policy. Energy Policy 2008;36(8):2887-902.

[22] Wei YM, Liao H, Fan Y. An empirical analysis of energy efficiency in China's iron and steel sector. Energy 2007;32(12):2262-70.

[23] WorldSteelAssociation. World steel in figures, 2009.

[24] Worrell E, Price L, Martin N. Energy efficiency and carbon dioxide emissions reduction opportunities in the U.S. iron and steel sector. Energy 2001;26(5):513-36.

[25] Worrell E, Price L, Martin N, Farla J,Schaeffer R. Energy intensity in the iron and steel industry: A comparison of physical and economic indicators. Energy Policy 1997;25(7-9):727-44.

[26] Zhang J, Wang G. Energy saving technologies and productive efficiency in the Chinese iron and steel sector. Energy 2008;33(4):525-37.

[27] Dahlmann P, Endemann G, Kerkhoff HJ, Lüngen HB. WegezurEffizienzsteigerung in der Stahlindustrie.StahlinstitutVDEh, Wirtschaftsvereinigung Stahl im Stahl-Zentrum. 2010.

[28] Integrated Pollution Prevention and Control (IPPC). BestAvailable Techniques Reference Document on the Production of Iron and Steel.European Commission. December 2001.

[x1] Joint Research Centre - Institute for Prospective Technological Studies (2012): Best Available Techniques (BAT) Reference Document for Iron and Steel Production, Industrial Emissions Directive 2010/75/EU (Integrated Pollution Prevention and Control). European Integrated Pollution Prevention and Control Bureau (EIPPCB) at the European Commission's Joint research Centre - Institute for Prospective Technological Studies Production and Consumption Unit, Sevilla, Spain. 